\title{
Perbandingan Tebal dan Analisis Kerusakan Perkerasan Lentur Menggunakan Program KENPAVE dan Metode Asphalt Institute
}

\author{
(Thickness Comparison and Deterioration Analysis of Flexible Pavement using KENPAVE \\ Program and Asphalt Institute Method)
}

\author{
DIAN SETIAWAN M, ANITA RAHMAWATI, IWAN BAGUS SETIAWAN
}

\begin{abstract}
The mechanistic-empirical method is one of the techniques used in the design of pavement thickness. Maospati-Sukomoro Road is the primary access to Magetan City which is traversed by heavy vehicle traffic. This research was conducted with the objective to design the pavement thickness and to analyse the pavement performance against fatigue cracking and rutting. Bina Marga 1987 and AASHTO 1993 were used as the empirical method in this research. The results then investigated with KENPAVE program as the mechanistic method. The calculations showed that the Bina Marga 1987 produce $\mathrm{Nd}$ value of $7,52 \times 10^{5}$ and $\mathrm{Nf}$ value of $5,77 \times 10^{12}$ whereas the AASHTO 1993 produce $\mathrm{Nd}$ value of $2,12 \times 10^{9}$ and $\mathrm{Nf}$ value of $1,42 \times 10^{11}$. The result indicated that the designed pavement thickness based on the Bina Marga 1987 method is unable to serve the planned traffic load and will be damaged if there is no immediate maintenance work. In another side, the designed pavement thickness based on the AASHTO 1993 method is capable of serving the planned traffic load.
\end{abstract}

Keywords: fatigue cracking, flexible pavement, kenpave program, pavement thickness, rutting

\section{PENDAHULUAN}

Infrastruktur jalan yang baik dapat menjadi tulang punggung peningkatan perekonomian suatu daerah. Demi tercapainya tingkat pelayanan, kenyamanan, dan keamanan pengguna jalan, maka diperlukan perencanaan dan perancangan jalan yang matang. Berkurangnya waktu dan biaya perjalanan serta peningkatan keselamatan merupakan hasil akhir dari sistem jalan yang dirancang dengan baik (Gupta dkk., 2015).

Perkerasan adalah kerak yang relatif stabil yang dibangun di atas tanah alami dengan tujuan untuk mendukung dan mendistribusikan beban kendaraan dan menyediakan lapis aus yang mencukupi (Ramyashree, 2016). Ruang lingkup utama dalam mendesain sebuah perkerasan jalan adalah meliputi pemilihan bahan penyusun dan menentukan ketebalan masingmasing lapisan guna memastikan bahwa lapisan perkerasan mampu melindungi tanah dasar dari beban kendaraan (Zakaria dkk., 2014).
Metode yang biasa digunakan dalam merencanakan perkerasan adalah metode mekanis dan empiris. Model mekanis didasarkan pada fisika dasar dan menentukan reaksi perkerasan terhadap beban roda dalam hal tegangan, regangan dan perpindahan. Sedangkan model empiris didasarkan pada respon perkerasan untuk meramalkan umur penggunaannya berdasarkan kinerja yang dihasilkan (Khavandi dan Ameri, 2009). Pendekatan berkelanjutan dan rasional dengan metode mekanis-empiris dapat memberikan solusi yang lebih baik, akurat dan lebih rasional untuk desain jalan (Gupta dkk., 2015).

Magetan merupakan sebuah Kabupaten yang terletak di kaki Gunung Lawu tepatnya di Provinsi Jawa Timur. Jalan MaospatiSukomoro merupakan jalan provinsi dan merupakan akses utama untuk masuk ke Kota Magetan, Ngawi dan Madiun. Letak kota Magetan yang berada di pegunungan mendorong wisatawan dari luar kota untuk berwisata atau sekedar melintas. Keberadaan jalan yang dibangun untuk menyambungkan Provinsi Jawa Timur dan Jawa Tengah atau 
yang sering disebut masyarakat sekitar "Jalan Tembus" tidak hanya dapat mempersingkat durasi perjalanan yang berimbas, namun di sisi lain juga berdampak pada meningkatnya volume kendaraan di Kota Magetan.

Selain itu di Kota Magetan telah banyak berdiri pabrik besar seperti Pabrik Kulit, Pabrik Gula dan Pabrik Tekstil yang memungkinkan kendaraan berat melintasi jalan MaospatiSukomoro. Kemacetan sering terjadi pada ruas jalan Maospati-Sukomoro terutama pada hari libur. Proyek pembangunan jalan "Twin Road" merupakan proyek yang terealisasi pada akhir tahun 2017 yang digagas oleh 'Pemerintah Kabupaten Magetan dengan tujuan untuk mengurai kemacetan di jalan MaospatiSukomoro. Jalan ini dijadikan sebagai lokasi penelitian tidak hanya berdasarkan pertimbangan pengamatan tentang kondisi volume kendaraan berat yang tinggi, namun juga terkait pentingnya untuk mengevaluasi kinerja jalan yang baru saja diresmikan tersebut.

Oleh karena itu, penelitian ini bertujuan untuk merancang tebal perkerasan jalan MaospatiSukomoro menggunakan metode Bina Marga 1987 dan metode AASHTO 1993. Kemudian terhadap hasilnya dilakukan analisis regangan tarik dan regangan tekan menggunakan program KENPAVE. Selanjutnya metode Asphalt Institute digunakan untuk mengevaluasi kemampuan struktur perkerasan dalam menahan kerusakan retak lelah (fatigue cracking) dan retak alur (rutting).

\section{Perkerasan Lentur}

Menurut Aminsyah (2010), perkerasan lentur terdiri dari agregat sebagai material dan aspal sebagai pengikat baik dengan atau tanpa bahan tambah. Material pembentuk aspal dicampur pada suhu yang telah ditentukan sebagaimana sesuai dengan jenis aspal yang digunakan. Pada umumnya komponen penyusun suatu perkerasan terdiri dari lapis permukaan, lapis pondasi atas dan lapis pondasi bawah. Lestari (2013) memberikan fungsi dari setiap lapisan tersebut yaitu :

a. Lapis permukaan, sebagai bahan perkerasan untuk menahan beban roda kendaraan, sebagai pelindung badan jalan dari kerusakan akibat cuaca, dan sebagai lapis aus. b. Lapis pondasi atas, sebagai bagian perkerasan yang mendukung lapis permukaan dan menyebarkan tegangan yang terjadi ke lapis pondasi bawah untuk selanjutnya disalurkan ke tanah dasar.

c. Lapis pondasi bawah, sebagai pendukung perkerasan dalam menyebarkan beban roda kendaraan dan mencegah tanah dasar masuk ke lapisan pondasi.

\section{Metode Bina Marga 1987}

Metode bina marga 1987 dalam perkembangannya lebih dikenal dengan sebutan metode analisa komponen. Metode ini merupakan modifikasi dari AASHTO 1972 revisi 1981. Hal yang perlu diperhatikan dalam merancang tebal perkerasan ini adalah sebagai berikut:

a. Lalu lintas, meliputi jumlah jalur, koefisien distribusi kendaraan, angka ekivalen, dan lalu lintas harian rata-rata.

b. Daya dukung tanah dasar dan CBR.

c. Faktor Regional, merupakan keadaan lapangan yang meliputi permeabilitas tanah, drainase, bentuk alinyemen dan presentase kendaraan berat, serta iklim.

d. Indeks permukaan, merupakan nilai dari tingkat pelayanan lalu lintas meliputi kerataan/kehalusan dan kekokohan permukaan jalan.

e. Koefisien kekuatan relatif.

f. Indeks tebal perkerasan, untuk mencari nilainya diperlukan plotting dari nilai yang telah ditentukan.

\section{Metode AASHTO 1993}

Metode AASHTO pertama kali dikenal pada tahun 1972. Metode ini pada awalnya merupakan sebuah penelitian berkelanjutan yang dibiayai oleh pemerintah federal (AASHTO, 1993). Metode ini pada dasarnya merupakan perhitungan dengan metode empiris dan merupakan metode perancangan tebal perkerasan yang berkembang di Amerika Serikat. Untuk merancang tebal perkerasan menggunakan metode AASHTO 1993, diperlukan beberapa parameter, diantaranya:

a. Structural Number (SN), merupakan fungsi dari koefisien relatif lapisan serta fungsi dari koefisien drainase. 
b. Lalu lintas, adapun pedoman yang digunakan adalah lalu lintas kumulatif selama umur rencana berlangsung. Nilai tersebut diperoleh dengan mengalikan kumulatif beban gandar standar selama satu tahun (W18) dengan pertimbangan parameter volume lalu lintas, umur rencana, serta pertumbuhan lalu lintas.

c. Reliability, merupakan tingkat probabilitas keberhasilan dari perkerasan dalam memenuhi fungsi sesuai dengan yang diinginkan. Salah satu fungsi yang dimaksud yakni menyediakan layanan tertentu berupa kinerja (Alsherri dan George, 1988).

d. Serviceability, merupakan tingkat kenyamanan pengguna jalan yang dirasakan selama melewati jalan tersebut.

e. Faktor lingkungan.

\section{Program KENPAVE}

Analisis KENPAVE merupakan perangkat lunak yang menggabungkan perkakas fleksibel kenlayer dan perkerasan kaku kenslab, dan memungkinkan penggunaan bahan elastis linier, nonlinier dan serta sifat viskoelastik untuk lapisan yang berbeda (Loulizi dkk., 2006). Sebelum KENPAVE dibuat, terdapat empat program grafis secara terpisah yakni Layerinp, Kenlayer, Slabsinp, Kenslab. Bersama program grafis lainnya keempat program tersebut dikombinasikan dalam program KENPAVE. KENPAVE ditulis dalam bentuk visual basic yang dapat dijalankan pada perangkat lunak (Huang, 2004).

\section{Metode Asphalt Institue}

Pada umumnya kerusakan suatu perkerasan jalan disebabkan oleh beban berlebih kendaraan dan pengaruh cuaca. Jenis kerusakan yang dianalisis dalam penelitian ini adalah retak alur (rutting) dan retak lelah (fatigue cracking). Dalam penelitian ini digunakan persamaan dari metode Asphalt Institute untuk mengetahui jumlah repetisi beban dari rutting dan fatigue cracking.

a. Retak alur (rutting), terjadi akibat deformasi permanen baik pada lapisan beraspal, maupun pada lapis pondasi dan lapisan tanah dasar (subgrade) dibawah aksi beban roda lalu lintas yang berulang ( $\mathrm{Al}$ Khatteb, dkk., 2011). Persamaan yang digunakan adalah sebagai berikut :

$\mathrm{N}_{\mathrm{d}}=1,365 \times 10^{-9} \times \mathcal{E}_{\mathrm{c}}^{-4,477}$

Dimana:

$\mathrm{N}_{\mathrm{d}}=$ Nilai repetisi beban rutting

$\varepsilon_{\mathrm{c}}=$ Regangan tekan vertikal pada bagian atas lapisan tanah dasar

b. Retak lelah (fatigue cracking), merupakan hubungan dari serangkaian retakan yang menimbulkan potongan-potongan kecil tidak beraturan yang terjadi akibat pembebanan ulang secara terus menerus (Adlinge \& Gupta, 2013). Persamaan yang yang diberikan oleh The Asphalt Institute untuk mengetahui jumlah repetisi beban berdasarkan regangan tarik di bawah lapisan permukaan adalah sebagai berikut :

$\mathrm{N}_{\mathrm{f}}=0,0796 \times \varepsilon_{\mathrm{t}}^{-3,291} \times \mathrm{E}_{\mathrm{AC}}{ }^{-0,854}$

Dimana:
$\mathrm{N}_{\mathrm{f}}=$ Nilai repetisi beban retak lelah
$\varepsilon_{\mathrm{t}}=$ Regangan tarik pada bagian bawah
$\mathrm{E}_{\mathrm{AC}}=\quad \begin{aligned} & \text { lapis permukaan } \\ & \text { Modulus elastisitas lapis permukaan }\end{aligned}$

Metode Penelitian

Penelitian ini mengupas tentang perancangan tebal perkerasan jalan dengan metode Bina Marga 1987 dan metode AASHTO 1993, dimana hasil perancangan selanjutnya ditindaklanjuti dengan analisis kerusakan menggunakan program KENPAVE dan metode Asphalt Institue. Dengan demikian, dapat diketahui tebal perkerasan rencana dan kemampuan jalan terhadap terjadinya kerusakan retak lelah (fatigue cracking) dan retak alur (rutting).

\section{Tahapan Penelitian}

Adapun tahapan dalam penelitian ini ditampilkan pada Gambar 1.

\section{Lokasi Penelitian}

Penelitian dilakukan pada Proyek Pembangunan Jalan "Twin Road" MaospatiSukomoro, Kabupaten Magetan, Jawa Timur. Proyek ini terbentang sejauh $7,3 \mathrm{~km}$. Lokasi penelitian ditampilkan pada Gambar 2. 


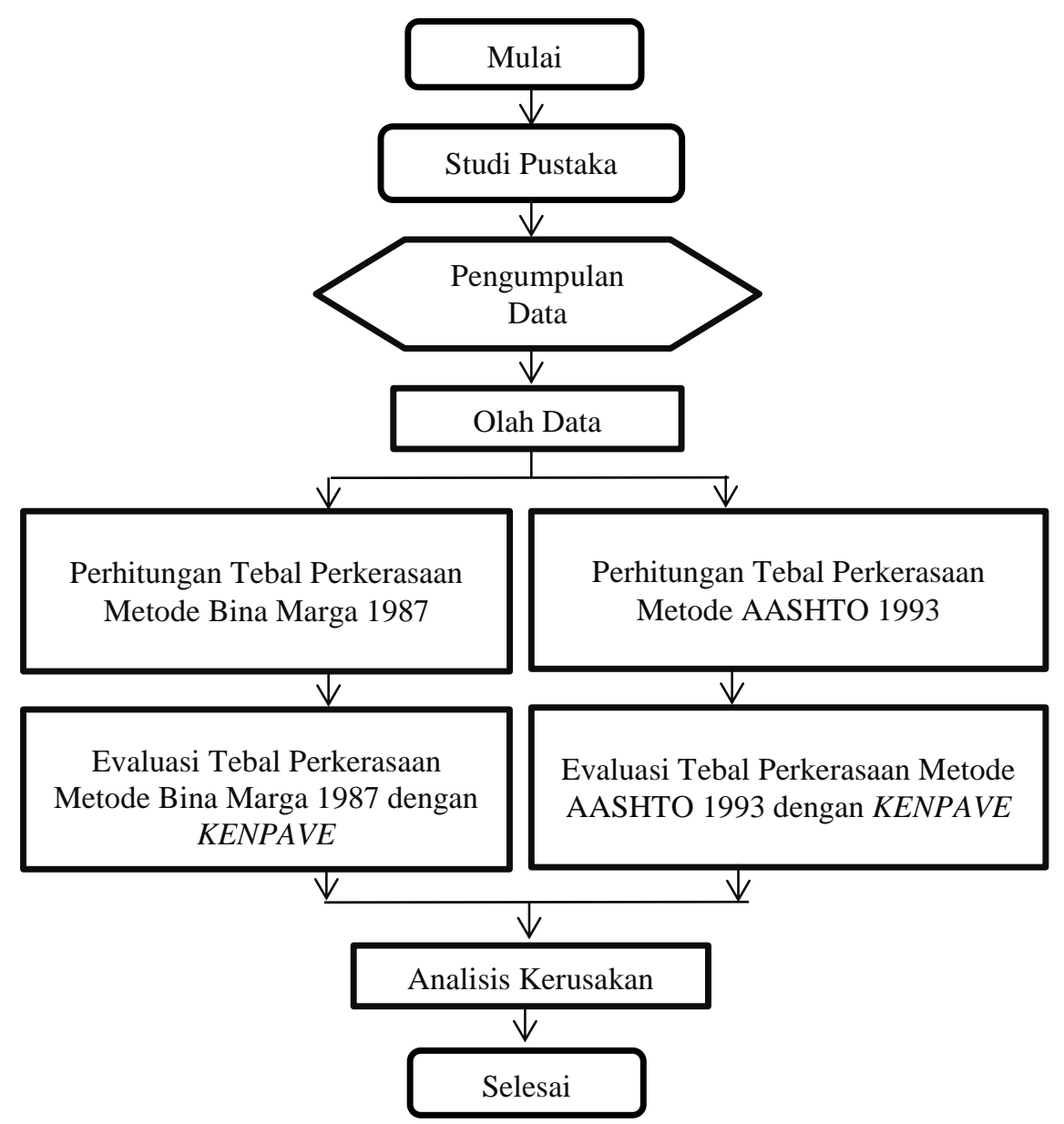

Gambar 1. Bagan Alir Tahapan Penelitian

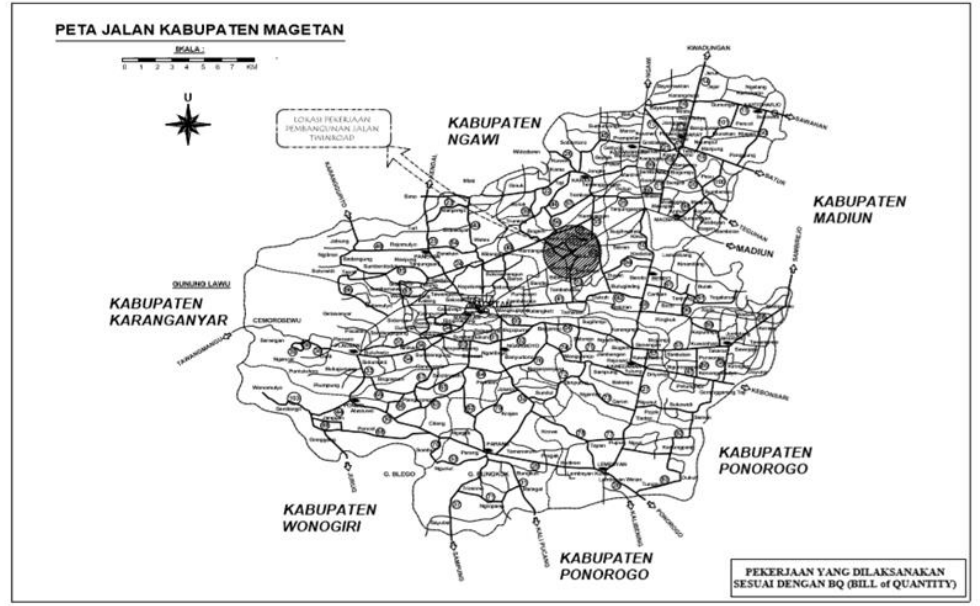

GAMBAR 2. Peta Lokasi Penelitian (Sumber: Dokumen proyek pembangunan jalan “Twin Road” Magetan, 2016)

\section{Jenis Data}

Data yang digunakan dalam penelitian ini menggunakan data sekunder proyek pembangunan jalan "Twin Road" MaospatiSukomoro dari Dinas Pekerjaan Umum Kabupaten Magetan. Data primer yang diperoleh merupakan hasil pengamatan langsung di lapangan untuk mendukung data sekunder yang didapatkan dari instansi yang bersangkutan. Adapun data yang dibutuhkan dalam penelitian ini antara lain:

a. Lalu lintas harian rata-rata (LHR)

Data LHR dalam penelitian ini diperoleh berdasarkan data primer yang dilakukan dengan pengamatan di lapangan (survei). Survei lalu lintas dilakukan pada jalan raya 
Maospati dengan durasi survei 12 jam per hari selama 3 hari.

b. Angka pertumbuhan lalu lintas (i)

Angka pertumbuhan lalu lintas diperoleh dari dokumen proyek Dinas Pekerjaan Umum Kabupaten Magetan yaitu sebesar $5,9 \%$.

c. Nilai CBR tanah

Nilai CBR tanah diperoleh dari dokumen proyek Dinas Pekerjaan Umum Kabupaten Magetan yaitu sebesar $6 \%$.

d. Curah Hujan

Berdasarkan dokumen proyek yang diperoleh dari Dinas Pekerjaan Umum Kabupaten Magetan, data curah hujan yang digunakan merupakan data dari Stasiun Hujan Jejeruk dan Stasiun Hujan Tinap yaitu rata-rata sebesar $115 \mathrm{~mm} /$ tahun.

\section{HASIL DAN PEMBAHASAN}

\section{Metode Bina Marga 1987}

Berdasarkan data primer dan sekunder yang diperoleh, selanjutnya dapat dilakukan perhitungan tebal perkerasan dengan parameter hasil yang ditampilkan pada Tabel 1. Hasil perhitungan tebal perkerasan lentur juga disajikan pada Gambar 3.

\section{Metode AASHTO 1993}

Berdasarkan parameter yang dibutuhkan dalam perancangan tebal perkerasan jalan metode AASHTO, maka diperoleh variabel-variabel penting tebal perkerasan yang disajikan pada Tabel 2 dan hasil tebal perkerasan yang divisualisasikan pada Gambar 3.

\section{Analisis Regangan Tarik dan Regangan Tekan Menggunakan Program KENPAVE}

Evaluasi dilakukan berdasarkan data hasil perhitungan tebal perkerasan yang telah direncanakan melalui metode Bina Marga 1987 dan AASHTO 1993. Selanjutnya dilakukan input pada program KENPAVE. Hasil nilai regangan tarik dan regangan tekan dari output program KENPAVE ditampilkan pada Tabel 3

\section{Analisis Kerusakan Menggunakan Metode Asphalt Institue}

Nilai regangan tarik dan regangan tekan yang diperoleh dari analisis program KENPAVE pada Tabel 3 digunakan untuk analisis selanjutnya menggunakan Persamaan 1 dan 2 dari metode Asphalt Institute untuk memperoleh nilai repetisi beban terjadinya retak alur/rutting $\left(\mathrm{N}_{\mathrm{d}}\right)$ dan retak lelah/ fatigue cracking $\left(\mathrm{N}_{\mathrm{f}}\right)$. Hasil perhitungan tersebut disajikan pada Tabel 4. Sedangkan pada Tabel 5 dapat dilihat hasil perbandingan beban lalu lintas rencana dan repetisi beban terjadinya retak lelah $\left(\mathrm{N}_{\mathrm{f}}\right)$ dan retak alur $\left(\mathrm{N}_{\mathrm{d}}\right)$ pada tebal perkerasan metode Bina Marga 1987 dan metode AASHTO 1993.

TABEL 1. Parameter Data Metode Bina Marga 1987

\begin{tabular}{lc}
\hline \multicolumn{1}{c}{ Parameter } & Keterangan \\
\hline Umur rencana & 20 tahun \\
\hline Pertumbuhan lalu lintas & $5,9 \%$ \\
\hline Tipe jalan & 4 lajur 2 arah \\
\hline CBR tanah dasar & $6 \%$ \\
\hline Daya dukung tanah dasar & 5 \\
\hline Lintas ekivalen rencana & 580,03 \\
\hline Faktor Regional & 1 \\
\hline
\end{tabular}

TABEL 2. Parameter Data Metode AASHTO 1993

\begin{tabular}{lc}
\hline \multicolumn{1}{c}{ Parameter } & Keterangan \\
\hline Reability & $90 \%$ \\
\hline Standar deviasi keseluruhan (So) & 0,45 \\
\hline $\mathrm{W}_{18}$ & $1.425 .596,92$ \\
\hline & $\mathrm{E}_{\mathrm{SG}}=9.000$ Psi \\
Modulus Resilien (Psi) & $\mathrm{E}_{\mathrm{SB}}=18.566,2$ Psi \\
& $\mathrm{E}_{\mathrm{BS}}=33.581,8$ Psi \\
\hline $\begin{array}{l}\text { Serviceabiityy atau Indeks } \\
\text { pelayanan }(\triangle \mathrm{Psi})\end{array}$ & 2,2 \\
\hline
\end{tabular}

TABEL 3. Hasil Analisis Regangan Tarik dan Regangan Tekan Menggunakan Program KENPAVE

\begin{tabular}{lcc}
\hline \multirow{2}{*}{ Tinjauan } & \multicolumn{2}{c}{ Nilai Regangan $(\varepsilon)$} \\
\cline { 2 - 3 } & Bina Marga 1987 & AASHTO 1993 \\
\hline Regangan tarik di bawah lapis permukaan $\left(\varepsilon_{\mathrm{t}}\right)$ & $2,38 \times 10^{-6}$ & $7,34 \times 10^{-6}$ \\
\hline Regangan tekan di bawah lapis pondasi bawah $\left(\varepsilon_{\mathrm{c}}\right)$ & $5,09 \times 10^{-4}$ & $8,64 \times 10^{-5}$ \\
\hline
\end{tabular}




\section{Perbandingan Hasil}

Hasil analisis perhitungan pada Gambar 3 menunjukkan bahwa perancangan tebal perkerasan menggunakan Metode AASHTO 1993 menghasilkan tebal lapis permukaan yang lebih tebal dibandingkan dengan tebal lapis permukaan yang dihasilkan oleh perhitungan menggunakan Metode Bina Marga 1987. Hal tersebut disebabkan karena analisis yang dilakukan pada Metode AASHTO 1993 cenderung menekankan berada pada lapis permukaan saja (Ferdian, 2008).

Perbedaan nilai tebal perkerasan yang dihasilkan oleh kedua metode tersebut turut dipengaruhi oleh perbedaan parameter yang diperlukan diantara keduanya. Pada metode AASHTO 1993, dalam menentukan daya dukung tanah diwakili atas nilai Modulus Resillient (MR), sementara itu pada metode Bina Marga 1987 parameter daya dukung tanah didasarkan atas nilai CBR (\%) yang mewakili. Selain pada parameter tanah, parameter yang berbeda adalah diantaranya pada metode Bina Marga 1987 yang dalam menentukan tebal perkerasan dipengaruhi oleh nilai Faktor Regional (FR), sedangkan dalam metode AASHTO 1993 tidak dipengaruhi nilai FR, namun dipengaruhi oleh nilai koefisien drainase. Nilai FR tersebut didasarkan atas kondisi curah hujan, kelandaian, dan jumlah persentase kendaraan berat yang melintas.

TABel 4. Hasil Analisis Repetisi Beban Retak Lelah $\left(\mathrm{N}_{\mathrm{f}}\right)$ dan

Retak Alur $\left(\mathrm{N}_{\mathrm{d}}\right)$ Menggunakan Metode Asphalt Institute

\begin{tabular}{lcccc}
\hline \multirow{2}{*}{ Tinjauan } & \multicolumn{2}{c}{ Nilai Regangan $(\varepsilon)$} & \multicolumn{2}{c}{ Analisis Kerusakan } \\
\cline { 2 - 5 } & Bina Marga 1987 & AASHTO 1993 & Bina Marga 1987 & AASHTO 1993 \\
\hline $\begin{array}{l}\text { Regangan tarik di bawah } \\
\text { lapis permukaan }\left(\varepsilon_{\mathrm{t}}\right)\end{array}$ & $2,38 \times 10^{-6}$ & $7,34 \times 10^{-6}$ & $\mathrm{~N}_{\mathrm{f}}=5,77 \times 10^{12}$ & $\mathrm{~N}_{\mathrm{f}}=1,42 \times 10^{11}$ \\
\hline $\begin{array}{l}\text { Regangan tekan di bawah } \\
\text { lapis pondasi bawah }\left(\varepsilon_{\mathrm{c}}\right)\end{array}$ & $5,09 \times 10^{-4}$ & $8,64 \times 10^{-5}$ & $\mathrm{~N}_{\mathrm{d}}=7,52 \times 10^{5}$ & $\mathrm{~N}_{\mathrm{d}}=2,12 \times 10^{9}$ \\
\hline
\end{tabular}

TABEL 5. Hasil Perbandingan Beban Lalu Lintas Rencana dan

Repetisi Beban Retak Lelah $\left(\mathrm{N}_{\mathrm{f}}\right)$ dan Retak Alur $\left(\mathrm{N}_{\mathrm{d}}\right)$

\begin{tabular}{|c|c|c|c|c|}
\hline \multirow[t]{2}{*}{ Metode } & \multirow{2}{*}{$\begin{array}{c}\text { Beban Lalu } \\
\text { Lintas } \\
\text { Rencana }\end{array}$} & \multicolumn{2}{|c|}{$\begin{array}{c}\text { Repetisi Beban Terjadinya } \\
\text { Keretakan }\end{array}$} & \multirow[t]{2}{*}{ Analisis Beban } \\
\hline & & $\mathrm{N}_{\mathrm{f}}$ & $\mathrm{N}_{\mathrm{d}}$ & \\
\hline Bina Marga 1987 & $1,42 \times 10^{6}$ & $5,77 \times 10^{12}$ & $7,52 \times 10^{5}$ & $\begin{array}{l}\text { Nf Memenuhi, Nd Tidak } \\
\text { Memenuhi }\end{array}$ \\
\hline AASHTO 1993 & $1,42 \times 10^{6}$ & $1,42 \times 10^{11}$ & $2,12 \times 10^{9}$ & Nf dan Nd Memenuhi \\
\hline
\end{tabular}

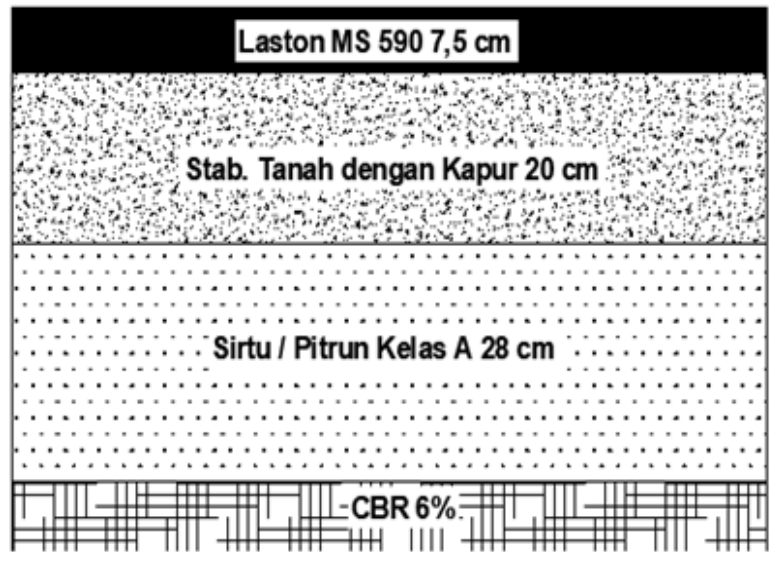

Metode Bina Marga 1987

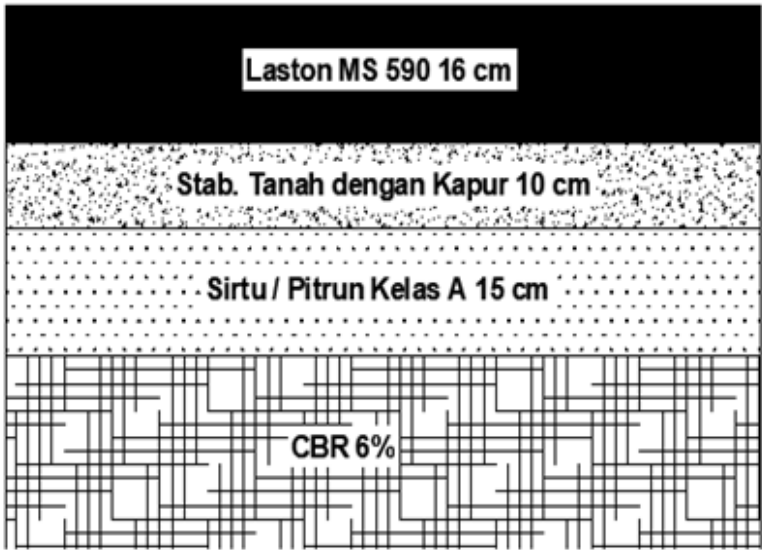

Metode AASHTO 1993

GAMBAR 3. Susunan tebal perkerasan metode bina marga 1987 dan AASHTO 1993 
Tabel 5 menunjukkan bahwa pada metode Bina Marga 1987, repetisi beban terjadinya retak lelah $\left(\mathrm{N}_{\mathrm{f}}\right)$ ialah sebesar $5,77 \times 10^{12}$, artinya nilai $\mathrm{N}_{\mathrm{f}}$ tersebut memenuhi persyaratan atau lebih besar dari beban lalu lintas rencana yang dipersyaratkan $\left(1,42 \times 10^{6}\right)$. Selanjutnya pada metode yang sama, repetisi beban terjadinya retak alur $\left(\mathrm{N}_{\mathrm{d}}\right)$ ialah sebesar $7,52 \times 10^{5}$, artinya nilai $\mathrm{N}_{\mathrm{d}}$ tersebut tidak memenuhi persyaratan atau lebih kecil dari beban lalu lintas rencana yang dipersyaratkan $\left(1,42 \times 10^{6}\right)$.

Sedangkan pada metode AASHTO 1993, repetisi beban terjadinya retak lelah $\left(\mathrm{N}_{\mathrm{f}}\right)$ ialah sebesar $1,42 \times 10^{11}$, artinya nilai $\mathrm{N}_{\mathrm{f}}$ tersebut memenuhi persyaratan atau lebih besar dari beban lalu lintas rencana yang dipersyaratkan $\left(1,42 \times 10^{6}\right)$. Dengan kata lain, kerusakan retak lelah akan terjadi pada saat jalan telah memenuhi beban lalu lintas rencana. Selanjutnya pada metode yang sama, repetisi beban terjadinya retak alur $\left(\mathrm{N}_{\mathrm{d}}\right)$ ialah $2,12 \times 10^{9}$, artinya nilai $\mathrm{N}_{\mathrm{d}}$ tersebut memenuhi persyaratan atau lebih besar dari beban lalu lintas rencana yang dipersyaratkan $\left(1,42 \times 10^{6}\right)$. Dengan kata lain, kerusakan retak alur akan terjadi pada saat jalan telah memenuhi beban lalu lintas rencana.

\section{KESIMPULAN}

Berdasarkan hasil penelitian yang telah dilakukan, diperoleh beberapa kesimpulan sebagai berikut:

a. Perancangan tebal perkerasan menggunakan Metode AASHTO 1993 menghasilkan tebal lapis permukaan yang lebih tebal dibandingkan dengan tebal lapis permukaan yang dihasilkan oleh perhitungan menggunakan Metode Bina Marga 1987.

b. Hasil analisis menunjukkan bahwa pada tebal perkerasan lentur hasil perhitungan metode Bina Marga 1987, kerusakan retak lelah akan terjadi pada saat jalan telah mencapai beban lalu lintas rencana. Sebaliknya, kerusakan retak alur akan terjadi pada saat jalan belum mencapai beban lalulintas rencana. Sedangkan pada tebal perkerasan lentur hasil perhitungan metode AASHTO 1993, disimpulkan bahwa kerusakan retak lelah maupun retak alur akan terjadi pada saat jalan telah mencapai beban lalu lintas rencana.

\section{DAFTAR PUSTAKA}

AASHTO. (1993). Guide for Design of Pavement Structures, Washington DC, American Association of State Highway and Transportation Officials.

Abdillah, S. H., Paransa, M. J., Jansen, F. \& Manoppo, M. R. (2013). Studi Pengaruh Pengambilan Angka Ekivalen Beban Kendaraan pada Perhitungan Tebal Perkerasan Fleksibel di Jalan Manado-Bitung. Jurnal Sipil Statik, 1(7).

Adlinge, S. S. \& Gupta, A. K. (2013). Pavement Deterioration and Its Causes. International Journal of Innovative Research and Development, 2(4), 437-450.

Al-Khateeb, L. A., Saoud, A. \& Al-Msouti, M. F. (2011). Rutting Prediction of Flexible Pavements Using Finite Element Modeling. Jordan Journal of Civil Engineering, 5(2), 173-190.

Alsherri, A. \& George, K. P. (1988). Reliability Model for Pavement Performance. Journal of Transportation Engineering, 114(3), 294-306.

Ameri, M. \& Khavandi, A. (2009). Development of MechanisticEmpirical Flexible Pavement Design in Iran. Journal of Applied Sciences, 9(2), 354-359.

Aminsyah, M. (2010). Pengaruh Kepipihan dan Kelonjongan Agregat Terhadap Perkerasan Lentur Jalan Raya. Jurnal Rekayasa Sipil, 6(1), 23-36.

Atkins, H. N. (2003). Higway Materials, Soils, and Concretes, Fourth edition, New Jersey: The Clarinda Company.

Badan Standarisasi Nasional. (2004). Geometri Jalan Perkotaan (RSNI T-14-2004), Jakarta.

Binamarga. (1987). Metode Analisa Komponen, Jakarta.

Binamarga. (2013). Manual Desain Perkerasan Jalan dengan Alat Benkelman Beam, Jakarta.

Dinata, D. I., Rahmawati, A. \& Setiawan, D. M. (2017). Evaluasi Tebal Perkerasan Lentur dengan Metode Analisa Komponen dari Bina Marga 1987 dan Metode $\quad$ AASHTO 1993 
Menggunakan Program KENPAVE (Studi Kasus: Jalan KarangmojoSemin Sta 0+000 sampai Sta 4+050). Jurnal Semesta Teknika, 20(1), 8-19.

Ferdian, T., Prasasya, A., Subagio, B. S. \& Hendarto, S. (2008). Analisis Struktur Perkerasan Lentur Menggunakan Program Everseries dan Metoda AASHTO 1993 Studi kasus: Jalan Tol Jakarta-Cikampek. Journal of Civil Engineering, 15(3), 133-142.

Gupta, A., Kumar, P. \& Rastogi, R. (2015). Mechanistic-Empirical Approach for Design of Low Volume Pavements. International Journal of Pavement Engineering, 16(9), 797-808.

Hardiyatmo, C. H. (2009). Perancangan Perkerasan Jalan dan Penyelidikan Tanah, Edisi Kedua, Yogyakarta: Gadjah Mada University Press.

Huang, Y. H. (2004). Pavements Analysis and Design, University of Kentucky, New Jersey, U.S.A: Prentice Hall.

Lestari, I. G. A. I. (2013). Perbandingan Perkerasan Kaku dan Perkerasan Lentur. Jurnal Transportasi, 7(1), 133-134.

Loulizi, A., Al-Qadi, I. L. \& Elseifi, M. (2006). Difference Between In-Situ Flexible Pavement Measured and Calculated Stresses and Strains. Journal of Transportation Engineering, 132(7), 574-579.

Putri, C. K. (2014). Prediksi Nilai Kerusakan Perkerasan Lentur dengan Metode Mekanistik-Empirik (Studi Kasus: Rekonstruksi JL. Arteri Selatan): Tesis Magister Sistem dan Teknik Transportasi, Universitas Gadjah Mada, Yogyakarta.

Ramadhan, M. E. (2017). Evaluasi Perancangan Tebal Perkerasan Jalan dengan Metode Analisa Komponen dan Metode Austroads Menggunakan Program KENPAVE (Studi Kasus Jalan Palbapang-Simpang Kweden STA 0+000-STA 2+650 dan Jalan Bakulan-Barongan STA 0+000-STA 3+198). Universitas Muhammadiyah Yogyakarta, Yogyakarta.

Ramyashree, P. H. (2016). Analysis on Performance of Terrazyme Stabilized
Soil by Using KENPAVE Software. International Journal of Engineering Science, 6(10), 2729-2732.

Simanjuntak, I. (2014). Evaluasi Tebal Lapis Perkerasan Lentur Manual Desain Perkerasan Jalan No. 22.2/KPTS/Db/2012 dengan Menggunakan Program KENPAVE. Jurnal Teknik Sipil, 3(2), 1-10.

Subagio, B. S., Karsaman, R. H. \& Nurwaida, I. W. (2003). Analisis Struktur Perkerasan Multi-Layer Menggunakan Program Komputer ELMOD Studi Kasus: Jalan Tol Jakarta-Cikampek. Journal of Civil Engineering, 10(3), 109-120.

Sukirman, S. (1999). Perkerasan Lentur Jalan Raya, Bandung: Penerbit Nova.

The Asphalt Institute. (1999). Asphalt Pavements for Highway \& Streets Manual Series No.1 (MS-1). $9^{\text {th }}$ Edition. Lexington.

Zakaria, N. M., Yusoff, N. I. M., Hardwiyono, S., Mohd Nayan, K. A. \& El-Shafie, A. (2014). Measurements of The Stiffness and Thickness of The Pavement Asphalt Layer Using The Enhanced Resonance Search Method. The Scientific World Journal, 1-8.

PENULIS:

Dian Setiawan M

Program Studi Teknik Sipil, Fakultas Teknik, Universitas Muhammadiyah Yogyakarta, Kabupaten Bantul, DIY.

Email: diansetiawanm@ft.umy.ac.id

Anita Rahmawati

Program Studi Teknik Sipil, Fakultas Teknik, Universitas Muhammadiyah Yogyakarta, Kabupaten Bantul, DIY.

Email: anita_ygy@yahoo.com

Iwan Bagus Setiawan

Program Studi Teknik Sipil, Fakultas Teknik, Universitas Muhammadiyah Yogyakarta, Kabupaten Bantul, DIY.

Email: bagussetiawaniwan@gmail.com 